\title{
Otrabalho alienado e a alienação mental: a reforma psiquiátrica no capitalismo
}

\section{Alienated work and mental alienation: the psychiatric reform in capitalismo}

\section{El trabajo alienado y la alienación mental: la reforma psiquiátrica en el capitalismo}

Jamila Zgiet ${ }^{1}$

\begin{abstract}
RESUMO: $O$ artigo faz um paralelo entre o trabalho alienado na perspectiva marxista e a alienação mental. Para levantar hipóteses sobre essa correlação, considera-se a dupla utilidade da instituição psiquiátrica, de isolar e tratar pessoas que apresentem comportamento desviante. Permanece, não apenas na saúde, mas nas diversas políticas sociais, a compreensão do trabalho - em seu sentido estrito - como único meio de acesso a direitos, e do salário como única forma de manutenção da vida. Os programas de assistência social destinados a pessoas impedidas de trabalhar - crianças, idosos e pessoas com deficiência - são uma manifestação dessa centralidade, pois a única possibilidade apresentada a essas pessoas é de sobrevivência com valores monetários pífios. No entanto, as pessoas com transtorno mental não têm sequer esses direitos no âmbito da política de assistência social no Brasil, o que revela uma incompreensão quanto à natureza dos transtornos mentais ou uma compreensão de que eles são, na verdade, desvios morais ou simulações com o objetivo de manter as pessoas afastadas do trabalho. A inserção e a manutenção no mercado de trabalho são consideradas indicadores positivos no âmbito da saúde, sendo um determinante social de saúde ou um sinalizador de alta médica e ou psicossocial. Por outro lado, o trabalho é um dos elementos mais estressores da contemporaneidade e o ambiente de trabalho é um dos mais propícios ao desenvolvimento de transtornos mentais. Este artigo dedica-se à tentativa de elucidar essas contradições, questionando em que medida a reforma psiquiátrica teria um potencial revolucionário diante dos desafios que emergem numa sociedade capitalista.
\end{abstract}

Palavras-chave: Reforma psiquiátrica, Saúde mental, Trabalho.

\begin{abstract}
This paper makes a parallel between the alienated work in the marxist perspective and mental alienation. To raise hypotheses about this correlation, it is considered the dual utility of psychiatric institutions, to isolate and to treat people who present deviant behavior. It remains, not only in health, but in several social policies, the understanding of work - in its strict sense - as the only mean of access to rights, and of salary as the only way of maintaining life. Social assistance programs for people who are prevented from working - children, the elderly and people with disabilities - are a manifestation of this centrality, since the only possibility presented to these people is survival with insignificant monetary values. Nevertheless, people with mental disorders do not even possess these rights in the scope of the social assistance policies in Brazil, which reveals a misunderstanding about the nature of mental disorders or an understanding that

1 Doutoranda em Política Social pela Universidade de Brasília, Assistente social na Secretaria de Estado de Saúde do Distrito Federal. Secretaria do Estado de Saúde do Distrito Federal. Brasília, Distrito Federal, Brasil. E-mail: jamilazgiet@gmail.com
\end{abstract}

ISSN 1982-8829 Tempus, actas de saúde colet, Brasília, 11(3), 130-143, 2017 - Epub mar, 2018 
they are, in fact, moral deviations or simulations in order to keep people away from work. The insertion and maintenance in the labor market are considered positive indicators in health, being a social determinant in health or a sign of medical and/or psychosocial discharge. On the other hand, work is one of the most stressful elements in contemporaneity and the workplace is one of the most conducive to the development of mental disorders. This paper attempts to elucidate these contradictions, questioning to what extent the psychiatric reform would have a revolutionary potential in the face of the challenges that emerge in a capitalist society.

Keywords: Psychiatric reform, Mental health, Work.

RESUMEN: El artículo realiza un paralelismo entre el trabajo enajenado en la perspectiva marxista y el desequilibrio mental. Para aplicar una hipótesis sobre esta correlación, se considera la doble utilidad psiquiátrica, de aislar y tratar a personas que manifiestan comportamientos desviados. Permanece, no solamente en la salud, sino también en las distintas políticas sociales, la comprensión del trabajo - en su sentido estricto - solo como medio de acceso a derechos, y del salario bajo una forma de manutención de vida. Los programas de asistencia social destinados a personas imposibilitadas de trabajar - niños, personas mayores y personas con insuficiencia - son la manifestación de este carácter central, el cual brinda únicamente la posibilidad de sobrevivir con valores monetarios insignificantes. Sin embargo, las personas con desorientación mental no obtienen ni siquiera estos derechos en el contexto de la política de asistencia social en Brasil, dejando observar una incomprensión en cuánto a la naturaleza de los trastornos mentales y la comprensión de que en verdad son desvíos morales - simulando con el objetivo de mantener las personas alejadas del trabajo. La inserción y el sustento en el mercado de trabajo se consideran indicadores positivos en el contexto de la salud, sirviendo, a su vez, como determinante social de salud o incluso como un indicio de alta médica y/o psicosocial. Por otra parte, el trabajo es considerado el elemento más estresante de la actualidad donde a su vez, el clima de trabajo es el que genera el desarrollo de trastornos mentales. Este artículo intenta dilucidar tales contradicciones, cuestionando en qué medida la reforma psiquiátrica presenta un potencial revolucionario entre los desafíos que emergen dentro de una sociedad capitalista.

Palabras clave: Reforma psiquiátrica, Salud mental, Trabajo.

\section{INTRODUÇÃO}

Dificilmente encontram-se bibliografias com a finalidade de debater a inserção da pessoa com transtorno mental no mercado de trabalho. Ao contrário, discutem-se as doenças mentais decorrentes do trabalho. No entanto, a relação já estabelecida entre trabalho e transtorno mental não se dá ao acaso. Evidentemente referimo-nos a um trabalho com características que permitem o adoecimento e que rejeitam o adoecido.

Embora haja essa rejeição ao sujeito em sofrimento psíquico, o Estado e as construções sociais determinam a necessidade do trabalho para o alcance de determinados direitos. Apesar de passados dois séculos das contribuições de Philippe Pinel para a psiquiatria, a lógica do tratamento moral ainda permeia as relações estabelecidas entre a sociedade e o louco.

É a partir dessa reflexão que se levantam aqui algumas teorias sobre o papel do trabalho na vida da pessoa com transtorno mental e sobre a forma como as reformas psiquiátricas o têm compreendido em suas proposições de modificações profundas na lida com o transtorno mental.

ISSN 1982-8829 Tempus, actas de saúde colet, Brasília, 11(3), 130-143, 2017 - Epub mar, 2018 
É no âmbito de uma sociedade capitalista ancorada na exploração da força de trabalho que as reformas psiquiátricas são elaboradas. Embora considerem-se os ganhos advindos de procedimentos inovadores em saúde mental, questiona-se, no âmbito macrossocial, o nível crítico alcançado por essas propostas quando extrapolam o hospital psiquiátrico e a própria psiquiatria. A centralidade do trabalho, tão questionada na atualidade, estaria em xeque em se tratando de direitos e políticas sociais? O que quer dizer reabilitação mental? Qual é o papel dos profissionais não médicos na condução prática das políticas de saúde mental após o advento da reforma psiquiátrica? Essas são algumas perguntas levantadas neste trabalho, para as quais encontramos respostas hipotéticas e ainda em nível exploratório.

\title{
1. Alienação mental e trabalho alienado
}

A concepção de alienação mental está diretamente relacionada a outros conceitos, como doença mental, transtorno mental, loucura e, mais recentemente, sofrimento psíquico. Ela parte obrigatoriamente da compreensão de normalidade, que, segundo Foucault (a1999) ${ }^{1}$, se refere à filiação dos indivíduos a um corpo social dito homogêneo, mas que tem como função hierarquizar, classificar e distribuir lugares. A normalização é, para o autor, a partir do século XVIII, uma forma de disciplinar e regulamentar, o que pode ocorrer por meio de uma legislação, por exemplo.

No entanto, Foucault diferencia lei e norma em cinco aspectos, destacados por Edgardo Castro $(2009, \text { p. } 310)^{2}$ :

\begin{abstract}
1) A norma refere os atos e as condutas dos indivíduos a um domínio que é, ao mesmo tempo, um campo de comparação, de diferenciação e de regra a seguir (a média das condutas e dos comportamentos). A lei, por sua vez, refere as condutas individuais a um corpus de códigos e de textos. 2) A norma diferencia os indivíduos em relação a esse domínio, considerado como um umbral, como uma média, como um optimum que deve ser alcançado. A lei especifica os atos individuais desde o ponto de vista dos códigos. 3) A norma mede em termos quantitativos e hierarquiza em termos de valor a capacidade dos indivíduos. A lei, no entanto, qualifica os atos individuais como permitidos ou proibidos. 4) A norma, a partir da valorização das condutas, impõe uma conformidade que se deve alcançar; busca homogeneizar. A lei, a partir da separação entre o permitido e o proibido, busca a condenação. 5) A norma, finalmente, traça a fronteira do que lhe é exterior (a diferença com respeito a todas as diferenças), a anormalidade. A lei, por seu turno, não tem exterior, as condutas são simplesmente aceitáveis ou condenáveis, mas sempre dentro da lei.
\end{abstract}

A diferença predominante entre lei e norma é, portanto, o nível em que ambas operam. A norma é coletiva e construída coletivamente, criando informalmente modos considerados corretos de agir e de ser. A lei torna isso aplicável aos indivíduos, na construção de um sistema de vigilância e controle, uma vez que se torna possível atribuir ao indivíduo culpa e responsabilidade por qualquer prática considerada desviante. É nesse aspecto que Foucault lembra a importância da medicina: "Desde o momento em que é uma sociedade da norma a que está se constituindo, a medicina, posto que ela é a ciência por excelência do normal e do patológico, será a ciência régia” $(1994, \text { p. } 76)^{3}$. 
Foucault (b1999) ${ }^{4}$ ainda considera outras duas formas de abordagem da norma: como regra de conduta, que se opõe à desordem, à excentricidade e ao desvio na ordem dos comportamentos; e como regularidade funcional, cujo oposto é o patológico, referente ao mau funcionamento do organismo. A psiquiatria dita as normas nesses dois níveis, amparada, no segundo, pela neurologia. Sob uma lógica mais pragmática, Loïc Wacquant aproxima-se dessa discussão, sem, no entanto, tratar especificamente da noção de normalidade. O autor, em parceria com Pierre Bourdieu (2013) ${ }^{5}$, aborda o imperialismo cultural, que, sob o modelo neoliberal, faz uso da mundialização de práticas e conceitos para determinar padrões:

Como as dominações de gênero e etnia, o imperialismo cultural constitui uma violência simbólica que se apoia numa relação de comunicação coerciva para extorquir a submissão e cuja particularidade consiste, neste caso, no fato de universalizar particularismos vinculados a uma experiência histórica singular, ao fazer com que sejam desconhecidos enquanto tal e reconhecidos como universais. (Bourdieu, Wacquant, 2013, p.83)

O imperialismo permite a difusão e a regulação das normas mundialmente. Antes que as nações adotem leis, os think tanks, sob a face de organismos internacionais, organizam o que é passível de normatização. Ressalta-se o fato de que os autores veem nesse processo uma violência simbólica, uma vez que a singularidade assume o status de anormalidade.

A alienação mental, por seu turno, é debatida por Foucault, o qual, sob a perspectiva da doença como anomalia, afirma que, para a psiquiatria clássica, trata-se de uma anormalidade em seu "estado puro", cristalizando condutas patológicas que alteram a personalidade do indivíduo (Castro, 2009, p. 32).

Compreende-se alienação mental como derivada de uma construção social, dependente das normas de uma sociedade. Cabe lembrar a relação que esse conceito guarda com o trabalho: a loucura só se tornou problema social a partir do momento em que o louco passou a ser visto como alguém sem utilidade, ou seja, no âmbito do capitalismo industrial, de uma sociedade baseada no trabalho. E o problema social da loucura eclode na hospitalização, na internação psiquiátrica.

O desenvolvimento do capitalismo, com a passagem ao capitalismo industrial no final do século XVIII e início do XIX, vai requerer uma massa de desocupados como instrumento da política salarial. Então, as instituições de clausura em massa deixaram de ser úteis e até se tornaram perigosas. Por isso, serão substituídas por um sistema hospitalar com dupla utilidade: por um lado, para aqueles que não podiam trabalhar por razões físicas e, por outro, para os que estavam impedidos por razões não físicas. (Castro, 2009, p. 68)

O asilo que antes carregava a carga moral e física da lepra passa a acolher uma doença não transmissível sob justificativas ora médicas, ora legais. Foucault compreende que a loucura é mais ampla do que fazem crer o capitalismo e a grande internação: "O doente mental não é a verdade finalmente descoberta do fenômeno da loucura, é o seu avatar propriamente capitalista na história etnológica do louco" (1994, p. 499).

ISSN 1982-8829 Tempus, actas de saúde colet, Brasília, 11(3), 130-143, 2017 - Epub mar, 2018 
Segundo o autor, a alienação priva o indivíduo do reconhecimento da verdade física e moral, deixando o doente mental excluído do mundo dos homens: ele passa da possessão, que teria atingido sua alma durante o Renascimento, ao status de despossuído de seu próprio corpo, que passa a ser submetido à instituição asilar.

Ainda que a sociedade não se reconheça no doente mental, o qual ela considera um estranho e um estrangeiro, é impossível dar conta da patologia mental sem se referir às estruturas sociais, sem ver seu meio humano como uma condição real da doença. [...]. As contradições do meio convertem-se em doenças só quando são contradições funcionais. Os conflitos sociais se tornam, desse modo, conflitos mentais (Castro, 2009, p. 261).

A partir dessa reflexão inspirada primordialmente em Michel Foucault, é possível recorrer a Dulce Whitaker $(1992)^{6}$, que sugere "a normalidade como patologia". A autora parte do pressuposto de que as doenças surgem a partir de um desequilíbrio diante da natureza e do ambiente sociocultural. No entanto, os desequilíbrios podem ser gerados pela própria cultura, que programaria os indivíduos de forma artificial por meio de uma "racionalidade", distante da natureza e da sua natureza. Logo, quanto maior a racionalidade, mais doença mental - ou mais irracionalidade. No entanto, o que seria mais irracional: ajustar-se a uma lógica artificial que afasta as pessoas da natureza e da própria natureza ou rejeitar esse ajustamento e viver de acordo com uma verdade própria? Segundo a autora, "quando mais ajustado ao sistema produtivo, quanto mais eficiente seja um cidadão, mais patológica a sua relação com o mundo" (Whitaker, 1992, p.191). A alienação mental aparece assim como alternativa à alienação do mundo do trabalho. Torna-se uma forma de razão diante da desrazão que é abandonar a própria natureza.

Sérgio Lessa (2006) ${ }^{7}$ afirma que as pessoas são o que elas fazem, são as relações que estabelecem entre si e com a história da qual participam. Sendo a sociedade uma produtora de mercadorias, os seres humanos tornam-se guardiões de mercadorias: enquanto os da classe dominante guardam o capital, o proletariado protege a própria força de trabalho, única mercadoria que possui. Os marginalizados e desempregados são guardiões miseráveis que não podem vender força de trabalho.

Sua compreensão da alienação em muito se aproxima daquela de cunho mental. Da mesma forma que a loucura termina por desumanizar o indivíduo perante à sociedade, analisando a população adequada ao modelo de produção, verifica-se um nível tal de artificialidade no cotidiano, que se torna possível notar a desumanização promovida pela exploração da força de trabalho. "[...] nossos destinos são determinados muito mais pelo dinheiro que criamos do que pela gravidade que não controlamos. O poder do dinheiro sobre nós vem de nós próprios e, todavia, parece que ele tem uma força tão descomunal que não poderia ser de modo algum humana" (Lessa, 2006, p. 5). Enquanto no dito popular, é louco quem "rasga dinheiro", considera-se racional perder mercadorias que poderiam alimentar populações inteiras, se não houver dinheiro que possa comprá-las. 
nuclear suficiente para destruir o mundo 99 vezes. Do ponto de vista militar, uma vez só seria mais do que suficiente. E isto foi feito porque, para nós, "guardiões das mercadorias", é mais "sensato" construir as bombas que sensatamente atender às necessidades humanas. Que coisa seria mais "razoável" que preparar nossa própria autodestruição do planeta Terra - se isto for lucrativo? (Lessa, 2006, p. 6)

Do ponto de vista da psiquiatria, é doentio planejar a própria morte. Do ponto de vista social, se for em nome do lucro, é normal, aceitável e até sadio. A legislação, que, como descreve Foucault, individualiza as normas, prevê punição a assassinos. No entanto, opções políticas que prejudicam nações inteiras e provocam a morte de milhares são consideradas práticas humanas justas, principalmente se medidas pela meritocracia.

\footnotetext{
O louco, em seu dolorido e debochado desarrazoamento, provoca, no fundo, uma reflexão sobre esta grande ilusão capitalista de dar sentido à vida através da acumulação de honras e bens materiais. Ouvir o louco pode ser ouvir um grito que ecoa dentro da alma não só como objeto de curiosa piedade ou nervoso temor, mas como um desafio à ilusória segurança de uma vida erigida sob o terreno movediço da busca de uma felicidade que se revela sempre e cada vez mais inalcançável. (Oliveira, Dorneles, 2005, p.26) ${ }^{8}$
}

Analisadas essas percepções teóricas, questiona-se de que modo o movimento de reforma psiquiátrica iniciado nos anos 1970 lida com a questão do trabalho e com a relação entre o sujeito diagnosticado com transtorno mental e a sociedade. No Brasil, apesar da expressão "reforma", esse movimento é interpretado, pelo menos no âmbito de sua elaboração teórica, como "uma proposição de mudança paradigmática - e não apenas mais uma proposta de modelo assistencial" (Bezerra Jr., 2007 , p. 243) ${ }^{9}$. No entanto, pergunta-se: em que medida a reforma psiquiátrica em curso promove uma crítica ao trabalho alienado? A negação da instituição "hospital psiquiátrico" apresentada por Franco Basaglia é suficiente para o respeito à verdade do louco num contexto de centralidade do trabalho? Ou o que se segue à negação da internação?

\section{Experiências de reforma psiquiátrica e o lugar do trabalho}

O italiano Franco Basaglia influenciou todo o mundo com sua proposta de abertura das portas de saída e fechamento das portas de entrada dos hospitais psiquiátricos. Não se pode negar a contribuição da Psiquiatria Democrática Italiana para toda a concepção que se tem atualmente do tratamento em saúde mental. Não é possível se furtar, entretanto, de apontamentos sobre seus métodos e questionamentos sobre suas consequências do ponto de vista da emancipação humana. Franco Rotelli, ao relatar sua experiência de desinstitucionalização na cidade de Trieste, na Itália, revela o sucesso da substituição de serviços fechados por serviços de base comunitária, abertos e mais bem distribuídos no espaço da cidade. As famílias são citadas como elemento fundamental para a ruptura com a instituição manicômio e com as formas desumanas - muitas vezes reproduzidas do ambiente hospitalar - de cuidado com o ente querido adoecido.

Do ponto de vista do cotidiano dos pacientes ou ex-pacientes de hospitais psiquiátricos, Rotelli $(1992)^{10}$ destaca a parceria com cooperativas de trabalho, as empresas sociais. O trabalho aparece 
como elemento terapêutico e desinstitucionalizador. $\mathrm{O}$ termo cidadania surge recorrentemente nas discussões sobre a reforma psiquiátrica em quaisquer nações, mas pouco é debatido sobre o seu significado prático. Aparentemente, o combate ao manicômio não tem se mostrado suficiente para garantir cidadania, autonomia e emancipação. Em crítica aos modelos implementados, Denise Dias Barros (1992) ${ }^{11}$ afirma haver um contágio da cultura manicomial, em que a psiquiatria reformada se torna "uma instituição difusa no tecido social, sem transformar ou rever os paradigmas que haviam criado o asilo. Embora a internação não ocorresse mais em macroinstituições, o doente continuou a viver sem condições para o exercício de direitos" (p. 174). Questiona-se aqui a que direitos esses autores se referem e o que entendem por cidadania.

Ao mesmo tempo em que se propõe revolucionária, a desinstitucionalização pensada por Franco Basaglia baseava-se no pressuposto da existência de pleno emprego para todos. Logo, a reabilitação, termo que remete à habilidade ou à habilitação funcional, erguer-se-ia sobre uma sociedade do trabalho. Rotelli (1992) considera a importância de que as pessoas desinstitucionalizadas "possam readquirir a possibilidade e a identidade de trabalho". "Mas não a qualquer preço" (p.165), complementa. Segundo ele, na implementação da reforma italiana, verificou-se uma abertura para inovações no âmbito do trabalho na Europa Ocidental.

\begin{abstract}
Mas a nossa filosofia é que se deve colocar pequenas coisas juntas, com poucos adeptos a cada uma dessas situações, tentando misturar as pessoas que têm problemas sérios com as pessoas que têm poucos problemas e buscando fazer a formação profissional, mas para o mercado no qual se trabalha muito naquilo a que nós chamamos de a mediação do objeto. Em outras palavras, naquilo que a relação não é só de pessoa a pessoa, mas através do objeto que se produz, da qualidade do objeto que se produz, a qualidade do modo como se produz esse objeto, e o fato de que seja um objeto para o mercado, ou seja, um objeto verdadeiro e não um objeto faz-de-conta. [...] eu não acho que se faça Saúde Mental ao produzir coisas inúteis [...], mas eu acho que é muito mais importante que uma pessoa se empenhe um ano para fazer uma coisa que pode ser vendida do que ela empregar um dia apenas fazendo uma coisa que não serve para ninguém. (Rotelli, 1992, p. 158)
\end{abstract}

É evidente que as cooperativas, ao menos na sua concepção, pretendem-se alternativas à exploração da força de trabalho, mas o que é passível de dúvida é, além da inserção num trabalho alienado, a associação entre tratamento e trabalho, entre reabilitação em saúde mental e trabalho. Afinal, assume-se ou não a "existência-sofrimento", que substituiria em certa medida a cura das doenças? O trabalho é a indicação última de sucesso em um tratamento? Qual trabalho?

A França, que em 1838 já tinha uma lei voltada aos alienados e alienistas, desenvolveu a partir dos anos 1970 a chamada Psiquiatria de Setor. Inspirada nos modelos de atenção à saúde física, pretendia aumentar a participação de outros profissionais no cuidado, a partir de uma lógica de prevenção, profilaxia, cura e pós-cura, com uma divisão do território pelas equipes. Embora seu discurso tivesse reproduzido experiências anglo-saxônicas, de priorização da saúde mental em detrimento da doença mental, os resultados da Psiquiatria de Setor foram muito diferentes daqueles observados na psiquiatria italiana reformada: os hospitais psiquiátricos se fortaleceram e era deles que emanavam as demandas às equipes do setor. Segundo Izabel Passos (2009) $)^{12}$, o modelo francês 
ampliou a segregação das pessoas com transtorno mental.

Nicolas Henckes (2007) ${ }^{13}$ descreve detalhadamente a elaboração da política de saúde mental francesa e afirma que a Psiquiatria de Setor começou a ser pensada ainda nos anos 1950 por jovens médicos, sob influência da Segunda Guerra Mundial e do desenvolvimento de estudos no campo da psiquiatria biológica, que se apropriou de uma farmacologia própria. Uma crítica feita pelo autor é quanto ao fato de a construção da Psiquiatria de Setor ter sido encabeçada por médicos que ocupavam cargos de gestão ou posições de destaque em entidades corporativas à época. Isso fez com que a política se detivesse em grande parte a dar à psiquiatria maior visibilidade perante as demais especialidades médicas.

O foco dos setores na lógica tradicional do tratamento - prevenção e cura - fez que esse modelo não fosse capaz de lidar com os pacientes crônicos, aqueles incapazes de retomar a vida que tinham antes do surgimento da doença ou incapazes de se reabilitar. No âmbito da medicina, esses sofrem com a insuficiência de recursos farmacêuticos que lhes permitam uma vida mais integrada à comunidade. Do ponto de vista das demais áreas da saúde mental, são pessoas que dificilmente demonstrarão respostas positivas por meio de acompanhamentos psicológicos ou de outras terapias. Não são, também, pessoas que produziriam materiais vendáveis, contrariando aquilo que Rotelli valoriza, que é a confecção de produtos com qualidade para o mercado. São consideradas, assim, um problema na psiquiatria e para o molde de cuidado proposto, pois não se enquadram no padrão de paciente esperado para os serviços.

Não só na França, mas também nos Estados Unidos, a atenção à saúde mental passou a se desenvolver sob a perspectiva da possibilidade de prevenir as doenças. A prevenção tinha relação direta com o tipo de cidadão que se desejava moldar (Alessi, Oliveira, 2005) ${ }^{14}$. Assim, evitar o transtorno mental e a cronificação seria ensinar as pessoas a permanecer adaptadas aos modos de vida condizentes à época e ao local. A cura também adotaria a mesma meta.

Relatos sobre a reforma psiquiátrica no Canadá sugerem a mesma linha de reflexão, mas com resultados diferentes conforme a localidade. Segundo Rotelli (1992), as experiências do Québec, da Dinamarca, da Holanda e da França são semelhantes na medida em que, apesar de uma proposta de desospitalização, construíram serviços ao redor dos hospitais sem promover desinstitucionalização de fato. Ele critica, nesses locais, a utilização da arte como terapia, e não para o mercado, que deveria ser o foco, segundo o autor.

O que se verifica é uma ênfase, insistente e acrítica em alguns aspectos, na inserção do indivíduo no trabalho como indicador de sucesso do tratamento em saúde mental. No Brasil isso é previsto na legislação mais recente sobre o assunto. A Lei 10.216/01 considera, entre os direitos da pessoa com transtorno mental o de "ser tratada com humanidade e respeito e no interesse exclusivo de beneficiar sua saúde, visando alcançar sua recuperação pela inserção na família, no trabalho e na comunidade" (Art. $2^{\circ}$, Parágrafo único, inciso II) [grifo nosso]. 
A lei utiliza a expressão "recuperação", que, embora distinta de "cura", pressupõe a possibilidade de voltar a ser o que ou quem se era ou de voltar a ter algo que se tinha, no caso a saúde mental. Tal recuperação é vinculada à inserção do indivíduo na família, no trabalho e na comunidade, sendo esse o meio pelo qual o indivíduo atingiria a saúde mental ou o seu mais completo estado de bem-estar psíquico, respeitando o conceito de saúde da Organização Mundial de Saúde (OMS) de 1948 (Scliar, 2007) ${ }^{15}$, ou a cura para o transtorno mental.

Em pesquisa realizada em 2005 por Jorge et al. (2006) ${ }^{16}$, profissionais de saúde mental puderam informar sua concepção de reabilitação psicossocial em entrevistas. O papel central do trabalho aparece em algumas manifestações: "na doença, ele é incapaz para o trabalho e o convívio social. A saúde mental é curar essa incapacidade"; "devemos recolocar o paciente com transtorno mental nas relações afetivas e sociais de trabalho" (p. 736-737). Os autores criticam o fato de muitos profissionais reduzirem a compreensão de reabilitação à inserção no trabalho, enfatizando a importância de promover cidadania. O conceito desta, no entanto, não é mencionado. Aparentemente, trata-se de uma expressão de dignidade humana, relacionada ao respeito aos direitos básicos das pessoas.

Benedetto Saraceno $(1998)^{17}$, importante pensador da reforma psiquiátrica italiana, critica, como Rotelli, citado acima, o uso de arte como terapia:

\footnotetext{
Reabilitação para quê? E uma técnica? Fazer bonecos, pinturas? Isso não é reabilitação, é uma atividade das pessoas. Institucionalizar essas atividades é um grande perigo. Eu estou de acordo que os psicóticos façam pinturas, mas não estou de acordo que exista a pintura terapêutica. Eu estou de acordo que os psicóticos façam música, mas não creio na musicoterapia; que os psicóticos façam teatro, mas não creio na teatroterapia. $\mathrm{O}$ teatro, a pintura, a música são legítimos campos de expressão das pessoas. Nós não necessitamos de psicóticos pintores, necessitamos de psicóticos cidadãos. Não necessitamos de psicóticos artistas, necessitamos de psicóticos cidadãos. E, como qualquer cidadão, que sejam artistas ou não, mas não enquanto psicóticos, e sim enquanto cidadãos (p. 27).
}

Saraceno propunha às pessoas com sofrimento psíquico um trabalho gerador de sentido. A partir da crítica à clínica tradicional, que remete ao latim "clynos" - leito -, o autor discorre sobre uma prática de reabilitação de escuta e acompanhamento em que o sujeito não seja visto como passivo e destituído de poder e em que predomine a preocupação com o nível real material do paciente: "Uma clínica que permita ao paciente produzir valor social. Que seja a pintura, que seja a cooperativa de trabalho, que seja algo, mas que produza valor" (SARACENO, 1998, p. 30). O valor aí compreendido é concreto, mas também simbólico, uma vez que o trabalho vem com a missão de produzir sentido. Em que tipo de trabalho ocorre produção de sentido senão no trabalho não alienado?

\section{Por uma revolução no campo da saúde mental}

Os valores que elevam o trabalho como prática dignificante são relativamente recentes. Segundo André Gorz (2003) $)^{18}$, o que chamamos trabalho é uma invenção da modernidade, 
generalizado pelo industrialismo.

O "trabalho", no sentido contemporâneo do termo, não se confunde nem com os afazeres, repetidos dia após dia, necessários à manutenção e à reprodução da vida de cada um; nem com o labor, por mais penoso que seja, que um indivíduo realiza para cumprir uma tarefa da qual ele mesmo e seus próximos serão os destinatários e os beneficiários; nem com o que empreendemos por conta própria, sem medir nosso tempo e realizar em nosso lugar. $[\ldots]$

Pois a característica mais importante desse trabalho - aquele que "temos", "procuramos", "oferecemos" - é ser uma atividade que se realiza na esfera pública, solicitada, definida e reconhecida útil por outros além de nós e, a este título, remunerada. [...] Por isso, a sociedade industrial pode perceber a si mesma como uma "sociedade de trabalhadores", distinta de todas as demais que a precederam (GORZ, 2003, p. 21).

O mesmo autor lembra que o trabalho não era fator de integração social, mas o contrário, e aqueles que o realizavam eram considerados inferiores, porque estavam afastados da possibilidade de envolver-se com os assuntos da política. Utilizando-se de Hannah Arendt, Gorz afirma, ainda, que o trabalho "era indigno do cidadão" (ibidem, p. 22).

Hannah Arendt diferencia labor, trabalho e ação. O primeiro seria inerente à vida humana, tem a ver com as necessidades que se impõem ao indivíduo, sendo correspondente ao desenvolvimento biológico. "A condição humana do labor é a própria vida" (Arendt, 2007, p. 15) 19. O trabalho, por seu turno, vincula-se ao que a autora considera artificialismo. "O trabalho produz um mundo 'artificial' de coisas, nitidamente diferente de qualquer ambiente natural" (ibidem, p. 15). Apenas no nível da ação é que o ser humano se desenvolve politicamente.

O labor assegura não apenas a sobrevivência do indivíduo, mas a vida da espécie. O trabalho e seu produto, o artefato humano, emprestam certa permanência e durabilidade à futilidade da vida mortal e ao caráter efêmero do tempo humano. A ação, na medida em que se empenha em fundar e preservar corpos políticos, cria a condição para a lembrança, ou seja, para a história. (Arendt, 2007, p. 16)

A autora afirma que a expressão vita activa, que antes designava a ação humana de caráter político, passou, com o fim da antiga cidade-estado grega, "a denotar todo tipo de engajamento ativo nas coisas deste mundo" (ibidem, p.22). Isso não significa, lembra ela, que o trabalho e o labor tenham sido elevados na hierarquia das atividades humanas. A contemplação é considerada o único modo de vida realmente livre e digno.

A expressão do trabalho como condição de dignidade é um aspecto que nos leva a questionar a compreensão de cidadania adotada pela chamada reforma psiquiátrica em diversos países do Ocidente.

Ainda que, no âmbito da saúde, as legislações tenham se adequado à dita "humanização" da prestação de serviços - com todas as limitações advindas da formação dos profissionais, da estrutura dos equipamentos públicos e da própria noção da sociedade sobre a loucura, ainda enclausurada em

ISSN 1982-8829 Tempus, actas de saúde colet, Brasília, 11(3), 130-143, 2017 - Epub mar, 2018 
manicômios mentais (Pelbart, 2009) 20 $^{20}$, as demais políticas pouco têm mudado suas concepções sobre as pessoas com transtorno mental e dificilmente as acolhem. Assim, a rede de serviços, que deveria estender-se para além da saúde mental, permanece num nível quase utópico.

O trabalho assalariado vincula-se diretamente à noção de dignidade e de direitos. É nesse trabalho que se concentra a moralidade esperada do pobre. E são limitados os impedimentos considerados válidos para manter afastados do mercado de trabalho alguns grupos da sociedade, uma vez que crianças, idosos e pessoas com alguns tipos de deficiência são liberadas do dever moral de trabalhar.

Ainda assim, quando as pessoas desempregadas - no perfil descrito acima ou não - recebem algum tipo de benefício socioassistencial, pressupõe-se que elas tenham interesse em permanecer afastadas do mercado de trabalho, o que sofre duras críticas morais e é claramente evitado pelas normas. Caso contrário, não haveria tantos trâmites nos órgãos de perícia médica e ou social e as famosas "filas do INSS" no Brasil.

Na realidade brasileira, vemos, portanto, diversas políticas e programas voltados a pessoas com deficiência, inclusive mental, a qual se diferencia do transtorno mental do ponto de vista médico-biológico, mas nem tanto quando consideradas as funcionalidades físico-intelectuais. A concessão do Benefício de Prestação de Continuada está limitada a determinados códigos da Classificação Internacional de Doenças (CID-10), que pressupõem perda cognitiva. Logo, enquanto o chamado "retardo mental" não aparecer como comorbidade, paralela ao transtorno mental, não há previsão de suporte ao cidadão em tratamento psiquiátrico e ou psicossocial no sentido de afastá-lo da obrigatoriedade da atividade laborativa.

Outros direitos, como a concessão de passe livre em transporte local ou interestadual, também se destinam, na lei, apenas para as pessoas com deficiência e idosos. No Distrito Federal, consta no formulário de solicitação espaço para que o médico informe o "grau da deficiência" e o "nível de autonomia" do paciente, sendo necessário, no caso da deficiência intelectual, anexar laudo especificando grau de convivência social e nível cognitivo. Esses são aspectos muitas vezes não aplicáveis a pessoas com transtorno mental que têm boa convivência e nenhuma perda cognitiva.

Isso não significa que essas pessoas estariam aptas ao trabalho, uma vez que a empregabilidade depende de diversos outros fatores. No caso do transtorno mental, muitas vezes reconhecem-se na pessoa capacidade elevada de comunicação e uma autonomia que permite que ela conduza sua vida, sem, no entanto, que ela atinja os requisitos necessários ao trabalho remunerado como o conhecemos.

Robert Castel $(1978)^{21}$, em sua análise sobre a ordem psiquiátrica, afirma que, sob o fundamento contratual liberal, “o indivíduo é sujeito autônomo enquanto for capaz de se dedicar 
a intercâmbios racionais. Ou então sua incapacidade de entrar num sistema de reciprocidade o isenta de responsabilidade e ele deve ser assistido" (Castel, 1978, p. 34). Trata-se da mesma visão difundida pela Declaração Universal dos Direitos Humanos, de 1948, que reza, em seu Artigo $1^{\circ}$, que todos os homens são "dotados de razão e consciência e devem agir em relação uns aos outros com espírito de fraternidade".

O que se questiona aqui, quando abordamos a relação entre a pessoa com transtorno mental e o trabalho remunerado e, portanto, alienado, é a obrigatoriedade do trabalho para a subsistência. Enquanto a legislação e mesmo o senso comum abordam um "direito ao trabalho", vê-se na prática, um trabalho que é dever, e não direito, e direitos que só são garantidos mediante o cumprimento da obrigação do trabalho.

A mesma moral dos pobres identificada nas críticas a iniciativas como o Programa Bolsa Família e outros voltados a pessoas com renda ínfima é a que se pode encontrar na discussão sobre os direitos da pessoa com transtorno mental fora do âmbito da saúde.

Segundo Hespanha e Matos (2000)22, a dimensão moral da questão, principalmente no grupo dos patrões, é "de que não se pode admitir que alguém receba ajuda em troca de nada" (p. 93). Segundo esses autores, esse é um dos motivos que levam diversos países a adotar políticas ativas de combate ao desemprego, caracterizadas principalmente pela difusão de cursos profissionalizantes voltados a esse público. São também consideradas políticas ativas ou de ativação as contrapartidas ou condicionalidades imputadas aos beneficiários, como a de frequência à escola no caso do Programa Bolsa Família no Brasil.

Cursos profissionalizantes e inserção no emprego são considerados a panaceia para todos os problemas sociais. O transtorno mental não elimina a obrigação do trabalho. Ao contrário, além do problema moral da não ocupação de um posto de trabalho, soma-se a dita imoralidade contida no próprio transtorno mental. Nesse sentido, pode-se pensar que a retirada dos loucos de manicômios solucionou um problema e criou diversos outros, dentre eles a dúvida sobre a existência de uma sociedade disposta a receber o louco e do louco disposto a encontrar e fazer parte da sociedade fora da instituição.

A reforma psiquiátrica, compreendida como mudança no padrão de atenção à saúde mental, só encontra viabilidade numa sociedade baseada na equidade e na cidadania interpretada como valor superior à inserção no trabalho, como garantia e acesso a direitos humanos, sociais e políticos. A tolerância não é suficiente para a garantia da convivência entre pessoas com transtorno mental e as demais pessoas. A única forma de promover direitos não é por meio de uma reforma psiquiátrica centrada nos serviços e nos profissionais, mas por meio de uma sociedade que compreenda a dignidade como advinda da humanidade e não da inserção no trabalho alienado. 


\section{CONSIDERAÇÕES FINAIS}

A fim de tecer proposições práticas sobre o cuidado com as pessoas com transtorno mental, devem-se considerar alguns aspectos. $\mathrm{O}$ primeiro diz respeito à peculiaridade do transtorno mental na relação da pessoa com o trabalho e o emprego. $\mathrm{O}$ fato de predominarem os estudos que associam transtorno mental ao trabalho e às suas relações não é trivial, nem por acaso. $O$ trabalho é e vem sendo um elemento estressor propulsor dos chamados transtornos mentais comuns - ansiedades e depressões. E isso só ocorre em relações de trabalho que envolvem subordinação, apropriação da força de trabalho por outrem e, consequentemente, alienação.

O transtorno mental não é como as doenças físicas, que têm diagnóstico e tratamentos delimitados, com resposta previsível do corpo. Embora os medicamentos contribuam - e muito para o alívio do sofrimento das pessoas com males psíquicos, não se trabalha em saúde mental - ou não se deveria trabalhar - com a noção de cura e recuperação completas. Assim, o trabalho pode, sim, ser um fator de promoção de saúde, desde que não seja adoecedor, desde que não provoque o agravamento do transtorno, desde que não signifique submeter pessoas a pressões e condições precárias de vínculo e trabalho.

O segundo aspecto é a participação do louco na sociedade. Na perspectiva do transtorno mental como doença crônica e das pessoas com transtorno mental como pessoas cuja existência não pode ser dividida entre loucura e normalidade, há, como para qualquer ser humano, as necessidades de circulação na cidade e de convivência familiar e comunitária. Logo, é necessário garantir a esse público direitos que permitam mobilidade, renda e convivência, não vinculadas obrigatoriamente ao trabalho.

Por fim, há a perspectiva da saúde em si. Os serviços de atenção à saúde mental precisam superar a lógica do tratamento moral e a compreensão reduzida da loucura como condição de saúde, passando a vê-la como condição de existência, sem a qual o indivíduo deixa de ser quem é. O atendimento em saúde mental deve ser o elo entre os indivíduos e a sociedade, deve facilitar, e não atrapalhar, a inserção dos sujeitos na vida comunitária. A abertura das portas de saída dos manicômios tem que ser acompanhada da abertura de portas de entrada em programas e serviços de outras políticas.

\section{REFERÊNCIAS}

$1 \quad$ Foucault M. Vigiar e punir. Petrópolis: Vozes; a1999.

2 Castro E. Vocabulário de Foucault: um percurso pelos seus temas, conceitos e autores. Belo Horizonte: Autêntica; 2009.

3 Foucault M. Ditos e escritos. Vol. 3. Paris: Gallimard; 1994.

ISSN 1982-8829 Tempus, actas de saúde colet, Brasília, 11(3), 130-143, 2017 - Epub mar, 2018 
6 Whitaker D. Cultura e doença mental. In: D'Incao MA, Organizadora. Doença mental e sociedade: uma discussão interdisciplinar. Rio de Janeiro: Graal; 1992.

7 Lessa S. Trabalho, sociabilidade e individuação. 2006 [Acesso em 04 jul 2015]. Disponível em http://sergiolessa.com/artigos_02_07/trab_indivi_fiocruz_2006.pdf

8 Oliveira WF, Dorneles P. Patrimônio e ambiente da loucura: a formação do profissional de saúde mental e o diálogo com a vida da cidade. In: Amarante P, Organizador. Archivos de saúde mental e atenção psicossocial 2. Rio de Janeiro: Nau; 2005.

9 Bezerra Jr B. Desafios da reforma psiquiátrica no Brasil. Physis 2007;17(2):243-50.

10 Rotelli F. Superando o manicômio: o circuito psiquiátrico de Trieste. In: Amarante P, Organizador. Psiquiatria social e reforma psiquiátrica. Rio de Janeiro: Fiocruz; 1992. p. 149-69.

11 Barros DD. Cidadania versus periculosidade social: a desinstitucionalização como desconstrução do saber. In: Amarante P, Organizador. Psiquiatria social e reforma psiquiátrica. Rio de Janeiro: Fiocruz; 1992. p. 171-95.

12 Passos IF. Reforma psiquiátrica: as experiências francesa e italiana. Rio de Janeiro: Fiocruz; 2009.

13 Henckes N. Le nouveau monde de la psychiatrie française. Les psychiatres, l'Etat et la reforme des hôpitaux psychiatriques de l'après guerre aux années 1970. Sociology. École des Hautes Études en Sciences Sociales (EHESS); 2007.

14 Alessi NP, Oliveira AGB. Cidadania: instrumento e finalidade do processo de trabalho na reforma psiquiátrica. Ciênc. Saúde Coletiva 2005 mar;10(1):191-203.

15 Scliar M. História do conceito de saúde. Physis 2007;17(1):29-41.

16 Jorge MSB, Randemark NFR, Queiroz MVO, Ruiz EM. Reabilitação psicossocial: visão da equipe de saúde mental. Rev Bras Enf 2006 nov dez;6(59):734-9.

17 Saraceno B. A concepção de reabilitação psicossocial como referencial para as intervenções terapêuticas em saúde mental. Rev Ter Ocup Univ São Paulo 1998 jan abr;9(1):26-31.

18 Gorz A. Metamorfoses do trabalho. São Paulo: Annablume; 2003.

19 Arendt H. A condição humana. 10. ed. Rio de Janeiro: Forense Universitária; 2007.

20 Pelbart PP. Da clausura do fora ao fora da clausura: loucura e desrazão. São Paulo: Iluminuras; 2009.

21 Castel R. A ordem psiquiátrica - a idade de ouro do alienismo. Rio de Janeiro: Graal; 1978.

22 Hespanha P, Matos AR. Compulsão ao trabalho ou emancipação pelo trabalho? Para um debate sobre as políticas activas de emprego. Sociologias $2000 \mathrm{dez}$ [acesso em 02 jul 2015];(4):88-108. Disponível em: http://www. scielo.br/scielo.php?script=sci_arttext\&pid=S1517-45222000000200005\&lng=en\&nrm=iso.

Artigo apresentado em 30/10/2017

Artigo aprovado em 09/01/2018

Artigo publicado no sistema em 16/04/2018

ISSN 1982-8829 Tempus, actas de saúde colet, Brasília, 11(3), 130-143, 2017 - Epub mar, 2018 